\title{
A Systematic Review of the Association Between Hospital Cost/price and the Quality of Care
}

\author{
Sara Jamalabadi ${ }^{1} \cdot$ Vera Winter $^{1,2} \cdot$ Jonas Schreyögg $^{1}$
}

Published online: 15 April 2020

(c) The Author(s) 2020

\begin{abstract} price and the quality of care. costs/prices and the quality of care. used to address confounding is more sophisticated.

\section{Introduction}

Providing high-quality healthcare services at a reasonable cost is among the main policy goals in many countries [1]. In recent decades, hospital reimbursement systems have undergone substantial revisions in many countries to reduce spending and increase the quality of care. Hence, hospital prices have been subject to changes. In general, hospital pricing mechanisms range from fee-for-service price lists
\end{abstract}

Background Limited empirical evidence exists regarding the effect of price changes on hospital behavior and, ultimately, the quality of care. Additionally, an overview of the results of prior literature is lacking.

Objective This study aims to provide a synthesis of existing research concerning the relationship between hospital cost/

Methods Searches for literature related to the effect of hospital cost and price on the quality of care, including studies published between 1990 and March 2019, were carried out using four electronic databases. In total, 47 studies were identified, and the data were extracted and summarized in different tables to identify the patterns of the relationships between hospital

Results The study findings are highly heterogenous. The proportion of studies detecting a significant positive association between price/cost and the quality of care is higher when (a) price/reimbursement is used (instead of cost); (b) process measures are used (instead of outcome measures); (c) the focus is on acute myocardial infarction, congestive heart failure, and stroke patients (instead of patients with other clinical conditions or all patients); and (d) the methodological approach

Conclusion Our results suggest that there is no general relationship between cost/price and the quality of care. However, the relationship seems to depend on the condition and specific resource utilization. Policy makers should be prudent with the measures used to reduce hospital costs to avoid endangering the quality of care, especially in resource-sensitive settings.

Electronic supplementary material The online version of this article (https://doi.org/10.1007/s40258-020-00577-6) contains supplementary material, which is available to authorized users.

Vera Winter

winter@wiwi.uni-wuppertal.de

1 Hamburg Center for Health Economics, University of Hamburg, Hamburg, Germany

2 Schumpeter School of Business and Economics, University of Wuppertal, Rainer-Gruenter-Str. 21, 42119 Wuppertal, Germany to global budgets, and diagnosis-related group (DRG) payments have spread across numerous countries [2]. DRG systems in various countries often rely on hospitals' cost information and are subject to changes over time. Theoretical works predict that increasing DRG prices provides incentives for hospitals to attract more patients [3]. Several empirical studies analyzed the impact of a change in reimbursement or price on hospital efficiency and the number of patients treated. For instance, Dafny [4] analyzed how hospitals respond to changes in DRG prices in the US and found no volume changes with DRGs subjected to the largest price increase. Street et al. [5] reviewed the impact of the introduction of a DRG system in Australia, Denmark, Norway, and Sweden. Their findings suggest that DRGs increased hospital efficiency by reducing the length of hospital stays and increasing hospital case volumes. Januleviciute et al. [6] investigated the impact of DRG price changes in Norwegian hospitals. Their findings provide evidence that hospitals react to this incentive by showing that an increase in prices leads to an increase in the number of patients treated. 


\section{Key Points for Decision Makers}

There is no general relationship between cost/price and the quality of care.

The relationship between cost/price and the quality of care seems to depend on the condition and specific resource utilization.

Policy makers should be prudent with the measures used to reduce hospital costs to avoid endangering the quality of care, especially in resource-sensitive settings.

Changes in price might also affect the hospital quality in several ways. First, if hospitals increase their volume after a price increase, the increase in volume could lead to a higher quality due to institutional learning effects [7, 8]. Additionally, higher prices might enable hospitals to spend more money (i.e. increase resources) on service provision, which might also have positive effects on the quality of care. However, hospitals might also be unwilling or unable to adjust their volume or resource input and instead maximize profits such that a price change has no effect on the quality of care.

Limited empirical evidence exists regarding the effect of price/price changes on hospital quality of care. Drawing upon evidence suggesting that a link exists between cost and quality appears to be fruitful because DRG prices in most countries are based on hospital cost information such that costs and prices are closely related. Several studies have investigated the cost-quality relationship, revealing highly heterogeneous characteristics and findings. This link is among the more controversial topics in health policy [9], and several potential mechanisms can explain the relationship between cost and quality. As outlined above, increases in resources (i.e. cost) could lead to quality increases. For instance, some technologies may lead to the increased use of medical personnel, material supplies, or training. In particular, some technologies may improve the efficiency of care delivery by reducing the procedure time, length of stay, or number of hospitalizations, thereby increasing the capacity of hospitals to treat additional patients. Consequently, the overall cost may increase, but such technology is likely to result in improved health outcomes for a higher number of patients. Some other technologies can help extend survival (e.g. in patients with life-threatening or chronic conditions), which may result in higher spending due to extended years of health-care utilization. However, in parallel, a given technology also allows individuals to live additional years with a higher quality of life or an improved health state, which could provide potential cost savings [10]. However, if resources are not used efficiently and effectively, changes in cost might be unrelated to the quality of care. In some instances, quality improvements may even decrease costs. Therefore, some technologies may reduce staff or time requirements or shift care to less costly care settings (e.g. inpatient to outpatient) while simultaneously improving the quality of care. For instance, percutaneous transluminal coronary angioplasty (PTCA) may facilitate a reduction in spending. The PTCA outcome improved following the introduction of coronary stents, leading to the reduced occurrence of restenosis, heart attacks, emergency coronary artery bypass grafting (CABG), and mortality [10]. In contrast, poor quality leads to more frequent readmissions and increased treatment of (avoidable) complications and hence, higher costs. Finally, the relationship between cost and quality might not be linear and unidirectional and might depend on the level of quality and cost. For instance, a $U$-shaped relation could exist in which increases in low levels of quality are associated with decreases in cost (if poor quality drives costs) until a certain threshold is reached; after reaching the threshold, further quality increases require increases in resources and, hence, higher cost. Simultaneously, one could imagine the opposite scenario in the form of an inverted $U$-shaped relationship in which quality increases initially require more resources and result in higher costs, and after a certain threshold is reached, synergy effects lead to increases in quality and simultaneous decreases in cost.

In summary, both price and cost can relate in various ways to hospital quality of care. In addition, several critical design characteristics may alter the association between cost/price and the quality of care [9]. Therefore, it is essential to separate the results based on defined key characteristics. In this study, we assess whether the results systematically vary depending on (i) the cost/price measures used; (ii) the quality measures used; (iii) the country in which the study was conducted; (iv) the clinical condition(s) investigated; and (v) the methodological approach used, particularly the degree to which studies approximate the causal effect based on the method used to address confounding.

We conducted a systematic review to synthesize the evidence regarding the association between hospital cost/price and the quality of care and identified sources of heterogeneity across studies. To date, only one systematic review performed by Hussey et al. [9] has analyzed the association between cost and the quality of care; however, some questions remain unanswered. First, their review only focuses on the association between cost measures and the quality of care; these authors do not consider price/reimbursement. Therefore, an overview of the price-quality relationship is lacking. Second, these authors exclude studies involving non-US data sources. Therefore, an overview of 
cross-country comparisons is lacking. Finally, an overview of whether the results differ depending on the clinical condition is lacking. This paper addresses these gaps in the literature and considers studies published since 2012, substantially increasing the quantity of evidence.

Accordingly, this study aims to provide an overview of the existing evidence regarding how price affects the quality of care in the hospital setting. Therefore, we conduct a literature review of studies analyzing the association between price and the quality of care in hospitals. However, because few studies investigating this relationship exist and prices often rely on the costs of hospital care, we additionally provide a literature review of studies investigating the relationship between hospital cost and the quality of care.

\section{Methods}

This review is reported in accordance with The Preferred Reporting Items for Systematic Reviews and Meta-Analyses [11] guidelines. A review protocol was developed to identify all published articles investigating the association between hospital cost/price and the quality of care.

\subsection{Search Strategy and Data Sources}

We defined the search process for each relationship ('costquality' \& 'price-quality') separately.

In the literature review of the cost-quality of care relationship, we first included all 29 studies identified by Hussey et al. [9] at the hospital level. Then, a three-step search process was used to identify new studies. First, by applying the problem, intervention, comparison, and outcome framework [12], we derived the primary keywords. Then, a limited preliminary search was performed using ScienceDirect, Scopus, and PubMed to analyze the primary keywords in the titles, abstracts, and keywords. Following this analysis, the final keywords were selected (the search was restricted to the titles and abstracts), and the search strategy was developed. The search strategy was tailored to individual databases based on their criteria but always followed the PICO framework (see Appendix A for the full electronic search strategy used to search PubMed as an example).

A systematic search was performed by following the search strategy using 4 electronic bibliographic databases, namely, PubMed (MedLine), Scopus, EconLit (ProQuest), and ScienceDirect, from 2012 to $2018,{ }^{1}$ and the search was repeated to identify studies published between 1990 and 2012 (the time horizon of Hussey et al. [9]), while the results were restricted to studies outside the USA.

Additionally, the references cited in the relevant studies were manually searched to identify additional relevant studies.
The retrieved articles were stored in EndNote (version X8). First, duplicate studies were excluded. Second, the title and abstract of each study were reviewed by two independent reviewers (SJ and VW) to exclude irrelevant articles. In cases where it was difficult to determine the relevance of an article based on the abstract, the full text was retrieved and examined by two reviewers (SJ and VW) independently to determine whether to include the paper. Then, the full texts of the relevant articles were examined by two reviewers (SJ and VW) separately using the selection criteria. All disagreements were resolved by either discussion or the involvement of a third researcher (JS).

For the literature review of the price-quality of care relationship, we conducted ad hoc searches and consultations with experts to derive an initial list of relevant studies, yielding four initial relevant studies [4, 13-15]. While attempting to derive keywords from these studies for a more systematic review, it became evident that the studies' wordings were highly heterogeneous such that no common keywords could be identified. Searching by terms, such as 'price', 'quality of care', and 'hospitals', yielded overflowing lists with less than $1 \%$ of the results being relevant to our context. Therefore, we decided to rely on backward and forward searching of the initial studies while assuming that we could identify the most relevant and influential studies concerning the "pricequality" association.

\subsection{Selection Criteria}

The studies were included if they were published, analyzed the association between cost/price and the quality of care in the hospital setting, employed quantitative methodology and were available (full text) in English.

We restricted the quality of care measurement to outcome and process measures as valid and reliable indicators of what actually occurs in medical practice [16]. Moreover, we restricted the cost/price measures to monetary measures. Eight studies included by Hussey et al. [9] were excluded because they relied on a care intensity index, which is a nonmonetary measure (4 studies), composite quality measure (i.e. composite measure of 30-day mortality and kidney transplant volume), which was not based on outcome or process measures (1 study), patient experience (1 study), caregiver rating of the patients' quality of death (1 study), and a structure measure (1 study).

No restrictions were imposed on the study design or duration. Articles were excluded if they were reviews or nonprimary articles (newspaper articles, editorials, book chapters, and conference abstracts).

\footnotetext{
$\overline{1}$ The authors continued to add new results up to March 2019.
} 


\subsection{Data Extraction}

To ensure that all data relevant to the question of interest of the review were collected, the data were entered into two tables. Table 1 provides information regarding the characteristics of each study, e.g. the population and data years. Another table (see Appendix C) provides information regarding each finding, i.e. association. As one study can have more than one finding, this table is more detailed and includes information regarding the type of cost/price measure, type of quality measure, and clinical condition investigated per association tested. All disagreements were resolved by either discussion or the involvement of a third researcher (JS).

The extracted data included the articles' title, author, year of the study, the country in which the study was conducted, samples and years of data collection, study design, clinical condition(s) investigated, types of quality measures, types of cost/price measures, methodological approach, and the direction of the association/causality between hospital cost/price and the quality of care. As some studies reported more than one result (i.e. different countries, conditions, and quality and/or cost measures), the number of data entries ("results," "associations") exceeds the number of studies.

\subsection{Data Analysis}

The extracted data were analyzed using a narrative format. As the studies were highly heterogeneous, a meta-analysis was not performed.

The main study outcome of interest was the direction and statistical significance of the reported association between the hospital cost/price and the quality of care. We evaluated the direction of the association by indicating whether the association was (significantly linear/nonlinear) positive, (significantly linear) negative, (significantly) U-shaped/ inverted U-shaped, or not significant.

Statistically significant $(p<0.1)$ results were classified according to the direction of the association. Some empirical studies revealed a simple, linear cost-quality relationship and assumed a constant marginal cost associated with quality improvement. A linear positive (negative) association implies that the higher the hospital cost/price, the higher (lower) the quality of care. If different ordered categories were compared with a reference group, when either at least $75 \%$ of the coefficients reported were significantly linear positive/negative or all coefficients were in the same direction with at least one being significant, the direction of the association was classified as positive/negative.

Additionally, some other studies assumed that the marginal cost may vary over the range of quality. These studies allowed for a nonlinear association between costs and quality by including the squared terms in their estimation model.
If the squared term was significant, the associations were coded as nonlinear. Such significant nonlinear associations were further categorized into the following three possible forms: (i) U-shaped relationship (i.e. in the lower range of quality, quality improves as costs decrease; however, after a certain threshold, higher quality can only be achieved with higher costs); (ii) inverted-U relationship (i.e. in the lower range of quality, quality improves with increasing costs; however, after a threshold, significant quality improvement can be achieved with relatively small increments in cost (decreasing marginal cost); and (iii) nonlinear positive relationship (i.e. quality improvement is achieved with increasing costs but decreasing marginal returns) (see Figs. 1 and 2). These forms were identified based on the authors' reports. In the results section, we merged the significant linear positive and nonlinear positive relationships due to their positive direction. Studies that did not find/report a significant result $(p>0.1)$ were coded as not significant.

The quality of care measures were classified into the following two categories: outcome (e.g. mortality, readmission, complication/morbidity, quality of life indexes, and composite measures) and process measurements. Process indicators vary depending on the clinical conditions investigated; therefore, we classified the process indicators based on the clinical condition [i.e. process measures for $\mathrm{CABG}$, pneumonia, congestive heart failure (CHF), acute myocardial infarction (AMI), and stroke]. For instance, two process measures for $\mathrm{CABG}$ are prophylactic antibiotic administered on the day of the intervention and antibiotic discontinued within $48 \mathrm{~h}$.

The cost measures were classified into the following two categories: (i) accounting costs reflecting the best use of hospital resources (measured by the providers' accounting system or cost-to-charge ratio) and (ii) costs due to inefficiency, i.e. costs associated with waste or inefficiency, obtained from a cost frontier analysis or data envelopment analysis. As very few studies assessed cost due to inefficiency, we do not differentiate the two categories in the results section.

The price measures were based on price/reimbursement, which reflects the payment that hospitals or other healthcare providers receive for providing medical services to patients (this could be a DRG-based payment or other reimbursement and price changes).

The clinical conditions were classified into the following 6 main categories: (i) AMI, (ii) CHF, (iii) pneumonia, (iv) stroke, (v) CABG, and (vi) hip replacement/fracture. We further aggregated various surgical procedures that had fewer than 5 associations into one category named other surgical procedures, which included vascular surgery, colectomy, abdominal aortic aneurysm repair, cholecystectomy, general surgery, orthopedic surgery, cardiothoracic or gastrointestinal operation, knee replacement surgery, varicose vein surgery, and groin hernia surgery. Moreover, we aggregated 


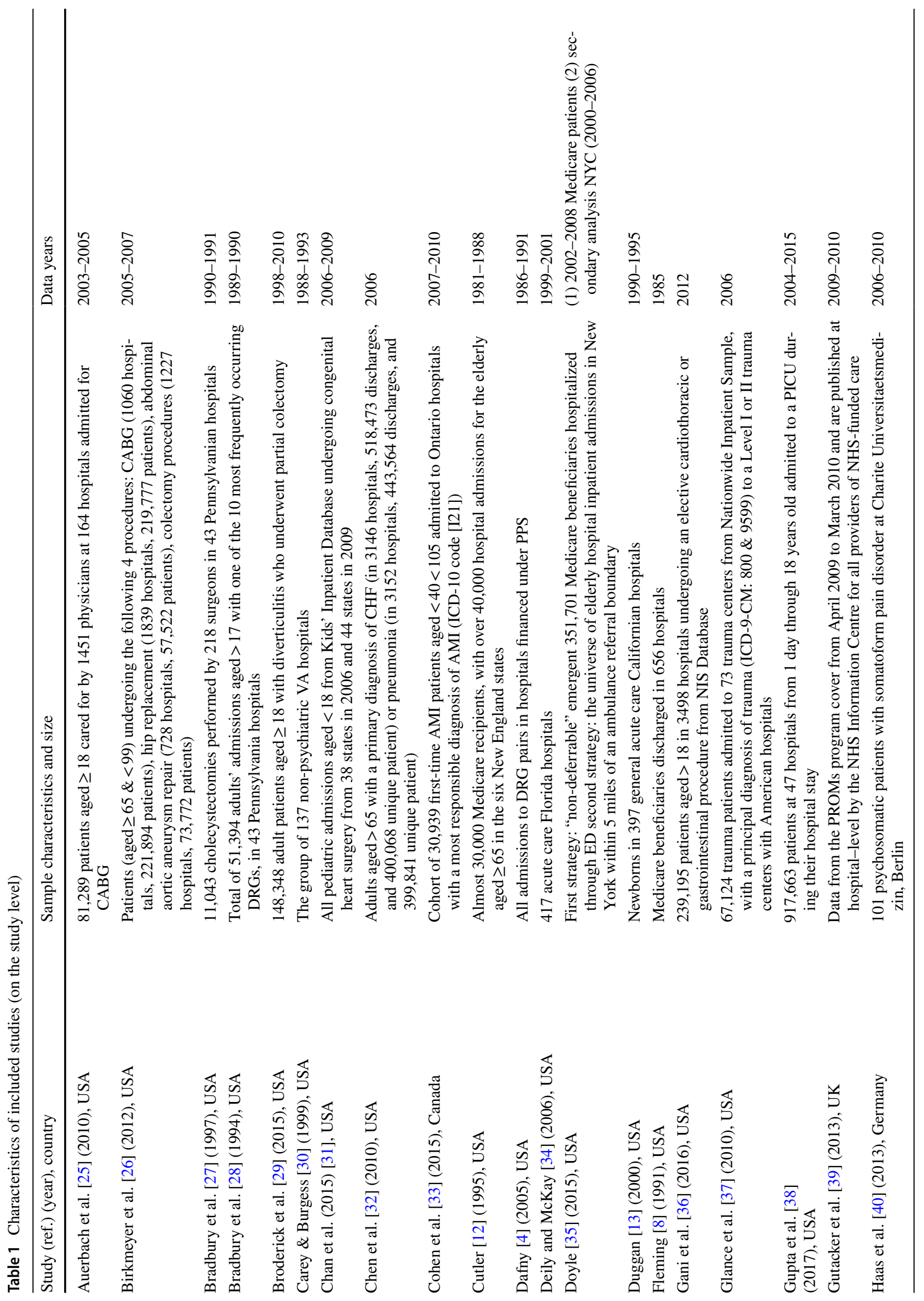




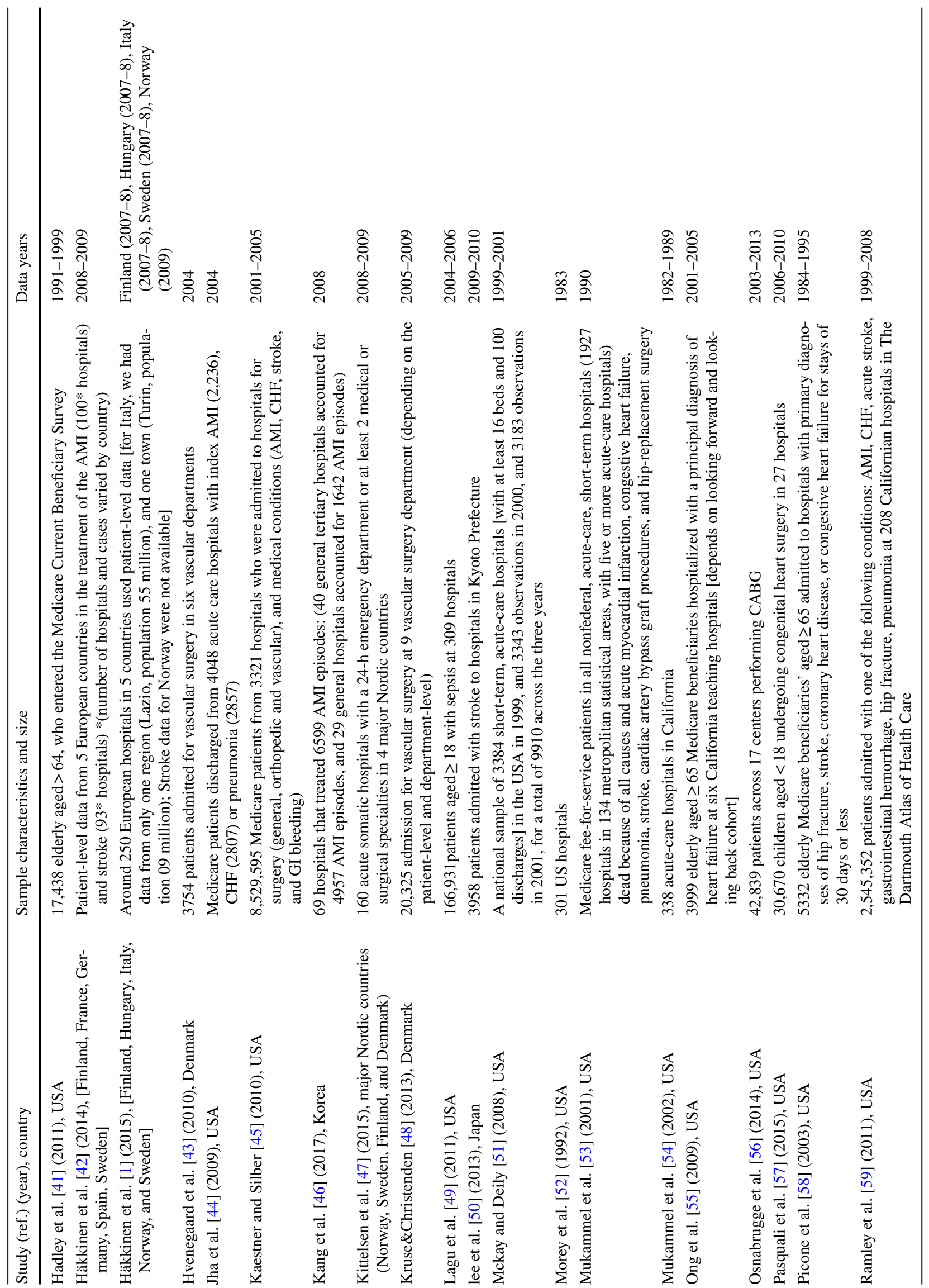


all diverse medical conditions with fewer than 5 associations into one category named other medical conditions, which included circulatory system diseases, cerebrovascular disorder, bronchitis and asthma, cardiac arrhythmia, angina pectoris, gastrointestinal hemorrhage, esophagitis, nutritional disorders, sepsis, emergency medical conditions, pediatric critical care, psychosomatic patients with somatoform pain disorder, and acute pancreatitis. Studies that either considered no specific conditions or all patients overall were categorized as indeterminate.

The countries were classified into twelve categories, including the USA, Canada, the UK, Germany, Italy, Spain, France, Hungary, Japan, Korea, Nordic countries (i.e. Sweden, Norway, Finland, and Denmark), and associations based on pooled sample countries.

The systematic search included the years between 1990 and 2018. We distinguished among the following three periods of approximately 10 years each: (i) 1990-1999, (ii) 2000-2009, and (iii) 2010-2018.

We classified the studies' methods by the degree to which they approximated the causal effect based on the method used to address confounding as follows: (i) experimental studies, including RCT and natural or quasi-experiments (e.g. difference-in-difference design); none of our reviewed studies used an experimental design; (ii) nonexperimental studies using techniques that control for unobservables, such as an instrumental variable approach; (iii) studies controlling for observables to adjust for confounding via a regression approach (e.g. panel or cross-section); and (iv) studies using a correlation analysis.

\section{Results}

In total, 4416 articles were retrieved from the systematic search for studies newer than 2012 and studies conducted outside the USA between 1990 and 2012. After removing duplicates, 2225 articles remained. Following the exclusion of articles based on the titles or abstracts, 54 articles were subjected to full-text reading. The full texts of the included studies were independently examined by two reviewers. On the basis of the inclusion and exclusion criteria, 22 articles were included through the systematic search (see Fig. 3). In addition, 21 studies included by Hussey et al. and four initial studies investigating the 'price-quality' relationship were added to our final review (i.e. a total of 47 studies). No additional articles were identified by searching the reference lists of these four studies. Moreover, all studies identified through the forward search had already been detected by the systematic search processes targeting the cost-quality relationship.

In total, 47 studies were included in the review, including nine studies that analyzed the price-quality relationship 
and 38 studies that assessed the cost-quality relationship. In these 47 studies, 225 associations between cost/price and quality measures were reported. The data extracted from the included studies are presented in Table 1, Appendix B (study level), and Appendix C (association level).

Most studies (66\%) were conducted in the USA, 29\% of the studies were conducted in Europe, and the remaining 5\% of the studies were conducted in Asia. Additionally, most studies (69\%) were published between 2010 and 2018.

The evidence regarding the association between cost/ price and the quality of care is summarized in Appendix C. The included studies were widely heterogeneous in terms of the cost measures, quality measures, clinical conditions, countries, and methods used to control for observables and unobservables.

Overall, 74 (33\%) associations between the unit cost/price and the unit quality were significantly positive, $33(15 \%)$ associations were significantly negative, $11(5 \%)$ associations were significantly U-shaped/inverted-U-shaped, and $105(47 \%)$ associations were not significant.

\subsection{Findings by Cost/price Measurement}

Among the included studies, cost/price was assessed via multiple indicators (Table 2). Of the 225 associations, 165 (73\%) were based on cost measures (accounting costs or costs due to inefficiency), while 60 (27\%) associations relied on price/reimbursement measures. Compared to the studies using cost measures, a larger share of the significant positive associations occurred in the studies based on price measures (33\% vs 37\%, respectively). Overall, the results of the associations were more mixed among the cost measure associations.

\subsection{Findings by the Quality of Care Measurement}

As presented in Table 2, the quality of care was assessed using different outcome and process indicators. The outcome indicators comprised the following five main categories: mortality, readmission, complication/morbidity, composite measures, and quality of life indexes. These five categories consist of several subcategories or different measures. Mortality comprises in-hospital, infant and posthospital mortality (i.e. 30-day, 6-month, 1-, 2- and 3-year mortality, and time to death with a maximum of 365 days). Readmission covers return periods of 14 days, 30 days, and one year. The quality-of-life indexes include generic PROM (such as the EQ-5D and EQ-VAS), condition-specific PROM (including the Oxford Hip Score, Oxford Knee Score, and Aberdeen Varicose Vein Questionnaire), the Health Activity Limitations index, and the overall functioning of mental health (MCS-8 score).

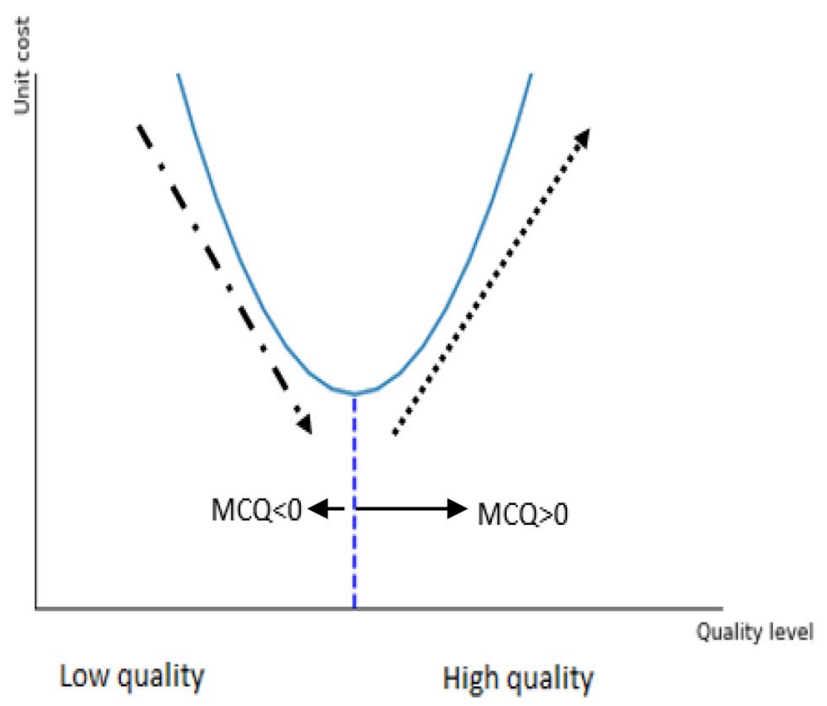

Fig. $1 \mathrm{U}$-shaped cost-quality relationship. $M C Q$ marginal cost of quality

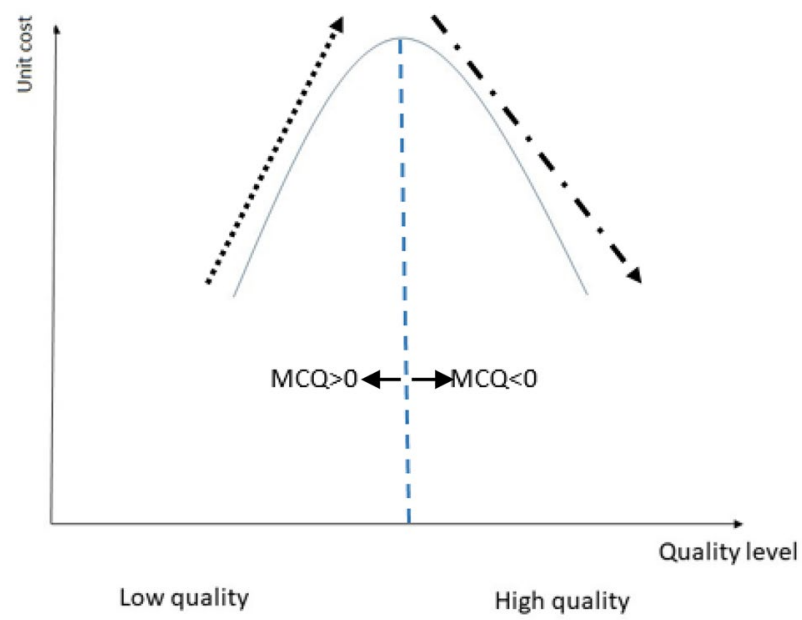

Fig. 2 Inverted u-shaped cost-quality relationship. $M C Q$ marginal cost of quality

In total, $192(85 \%)$ associations relied on the outcome quality of care measures, while only $33(15 \%)$ associations were based on process measures. The most commonly used outcome measure was mortality (140 of 192, 73\%). Among the 140 studies using mortality, most relied on the 30-day mortality (63 of 140, 45\%) or in-hospital mortality (57 of $140,41 \%)$.

The share of nonsignificant associations reported when process measures were used was lower than that when outcome measures were used (36-48\%). The shares of both significant positive and significant negative associations using process measures were higher than those using outcome measures. When further differentiating among the types of 
outcome measures, the share of significant negative associations was especially high using complications/comorbidities as the quality measure. This result is intuitive because as a negative quality outcome, complications have the highest potential to increase costs (i.e. the lower the quality and the greater the number of complications, the higher the costs).

\subsection{Findings by Clinical Condition(s)}

Of the reviewed studies, $89 \%$ focused on specific conditions, and the other $11 \%$ of the studies considered either no specific conditions or all patients. Of those that focused on specific condition(s), the most commonly studied conditions were surgical procedures (32 of 201, 16\%), AMI (30 of 201, $15 \%$ ), stroke ( 28 of $201,14 \%$ ), pneumonia ( 20 of $201,10 \%$ ), and CHF (19 of 201, 9\%). The most positive evidence of an association between cost/price and the quality of care was observed in AMI, CHF, and stroke. Among the 30 studies investigating AMI, 21 (70\%) found a significantly positive association; of the 19 studies investigating CHF, 12 (63\%) found a significantly positive association; and of the 28 studies investigating stroke, 14 (50\%) found a significantly positive association. Relatively higher shares of significantly negative associations were found in the other surgical procedures (12 of 32 associations, 38\%), CABG (4 of 11, 36\%), and pneumonia (6 of 20,30\%). The share of nonsignificant associations was especially high in the other medical conditions (32 of 49,65\%) and pneumonia (13 of 20,65\%).

\subsection{Findings by Country}

In total, 148 of 225 or $66 \%$ of all associations were based on US data. The second most frequent data source was Nordic countries (Denmark, Sweden, Finland, and Norway), with an aggregate of 32 associations. Only two other countriesJapan and the UK-yielded at least 10 associations. Among the countries with at least 10 associations, the findings of two data origins deviate substantially from the overall distribution of findings as follows: the Japanese data had a high share of significantly positive findings (6 of 10, 60\%), and the UK data had a high share of U-shaped associations $(27 \%)$.

\subsection{Findings by Year}

Most studies were conducted during the last period (from 2010 to 2018 , representing $69 \%$ of all associations), and the share of nonsignificant associations decreased over time (from $68 \%$ in $1990-1999$ to $40 \%$ in $2010-2018$ ). The most mixed results were reported during the period from 2000 to 2009 .

\subsection{Findings by Methodological Approach}

The included studies exhibited considerable heterogeneity in methodology. Of the 225 associations, 8 (4\%) studies used a correlation analysis, $163(72 \%)$ studies controlled for observables via a regression analysis (e.g. panel or crosssection), and 54 (24\%) studies controlled for unobservables using instrumental variables to address confounding.

As the degree of sophistication and approximation of the true causal effect increased, the share of nonsignificant associations decreased (from $75 \%$ in the studies using correlation analyses to $32 \%$ in the studies using IV analyses). Of all methods, the IV approach yielded the highest share of positive associations (50\% compared to $29 \%$ or less in the studies using other methods).

\subsection{Findings by Price Measurement Sub-section}

In the final step, we focused on the findings of studies using price, as these studies have not been previously subjected to a literature review. In particular, we aim to assess whether a distinct picture emerges regarding findings solely based on the price-quality relationship. The 60 associations included are divided by the previously used categorizations and summarized in Table 3. In total, as already displayed in Table 2, the associations are slightly more often significantly positive, and no study found a U-shaped relationship between price and the quality of care.

Regarding the quality-of-care measurement, 53 (88\%) associations relied on an outcome quality measure, while only $7(12 \%)$ associations were based on process measures. The most commonly used outcome measure was mortality $(40$ of $53,75 \%)$. Process measures were investigated only in the case of stroke, and when process measures were used, the share of nonsignificant associations was lower than that when outcome measures were used (14-39\%). Of the reviewed studies investigating the price-quality association, the most commonly studied conditions were medical conditions ( 24 of $56,43 \%$ ). The most positive evidence was observed in stroke, AMI, and CHF. In total, $83 \%$ of all associations were based on US data, and the Japanese data had a high share of significantly positive findings ( 6 of 9 , $60 \%$ ). Most studies were conducted during the last period (from 2010 to 2018, representing 50\% of all associations), and the share of nonsignificant associations decreased over time (from $85 \%$ in $1990-1999$ to $17 \%$ in $2010-2018$ ). Of all methods, the IV approach yielded the highest share of positive associations $(87.5 \%$ compared to $67 \%$ or less in studies using other methods). 


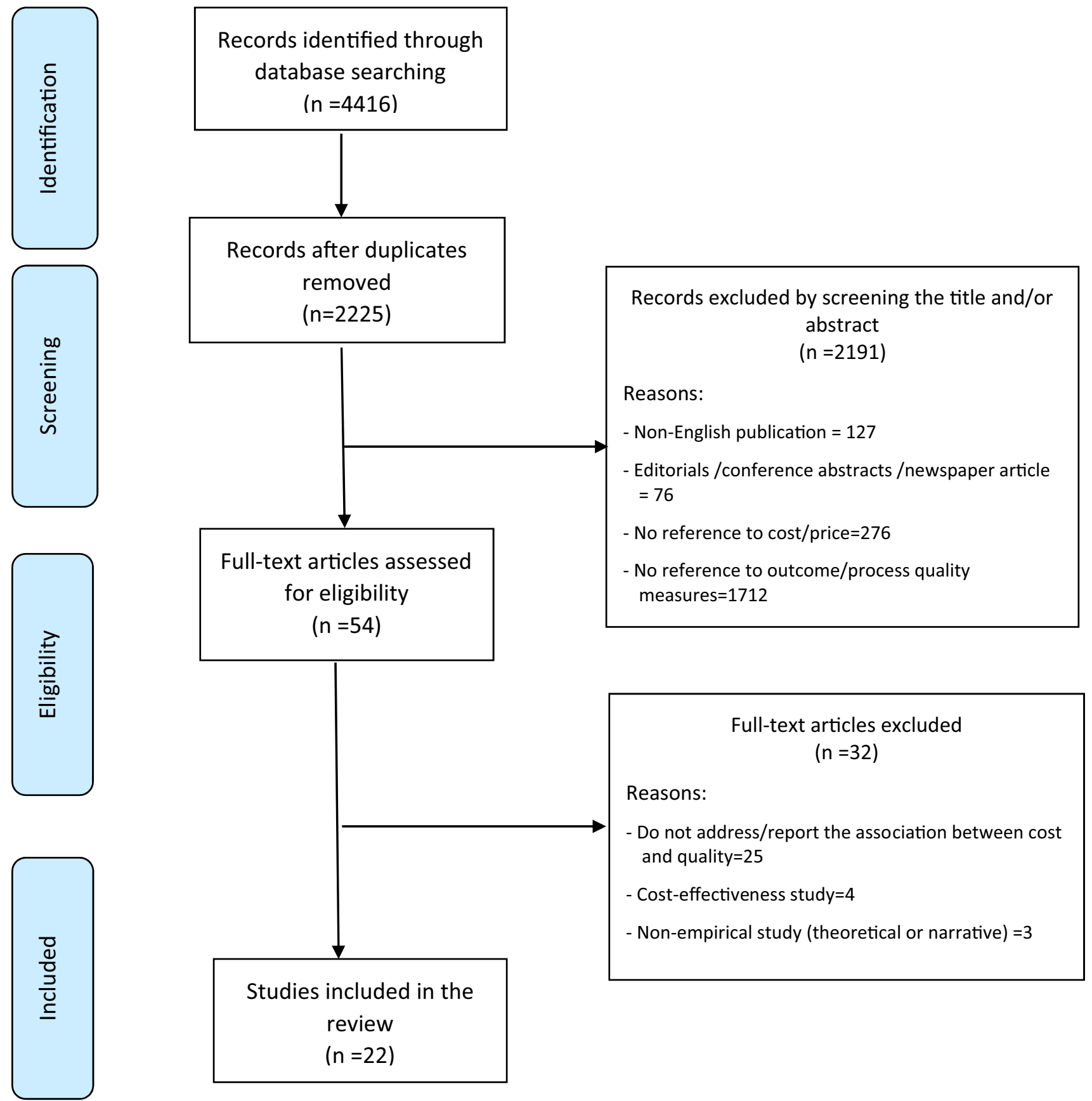

Fig. 3 Flow diagram of the literature search

\section{Discussion}

In this study, we conducted a systematic literature review to identify and summarize evidence regarding the association between cost/price and the quality of care in the hospital setting. To the best of our knowledge, this study represents the first comprehensive systematic literature review focusing on the association between cost/price and the quality of care that is not geographically restricted. The most frequent finding in our included studies was a nonsignificant association between price/cost and the quality of care ( $47 \%$ of all associations). We conducted a systematic review to synthesize the evidence regarding the association between hospital cost/price and the quality of care and identify sources of heterogeneity across studies. To date, only one systematic review performed by Hussey et al. [9] analyzed the association between cost and the quality of care and aggregated and reported the results at the study level [9]. Our findings 
Table 2 Overview on study findings on the cost/price-quality relationship in total and for different subcategories

\begin{tabular}{|c|c|c|c|c|c|}
\hline & $\begin{array}{l}\text { Sign linear/non- } \\
\text { linear positive }\end{array}$ & Sign linear negative & $\begin{array}{l}\text { Sign non-linear } \\
\text { U-shaped/ inverted } \\
\text { U-shaped }\end{array}$ & Not sign & $(n)(o r$ f 225$)$ \\
\hline & $(n)(\%$ of ni) & $(n)(\%$ of ni) & $(n)(\%$ of ni) & & $\left(n_{\mathrm{i}}\right)(\%$ of 225$)$ \\
\hline Total & $76(33 \%)$ & $33(15 \%)$ & $11(5 \%)$ & $105(47 \%)$ & $225(100 \%)$ \\
\hline \multicolumn{6}{|l|}{ Cost/price measure } \\
\hline Price/reimbursement & $22(37 \%)$ & $7(11 \%)$ & $0(0 \%)$ & $31(52 \%)$ & $60(27 \%)$ \\
\hline Cost (aggregate) & $54(33 \%)$ & $26(16 \%)$ & $11(6 \%)$ & $74(45 \%)$ & $165(73 \%)$ \\
\hline \multicolumn{6}{|l|}{ Quality of care measure } \\
\hline Outcome & $62(32 \%)$ & $26(14 \%)$ & $11(6 \%)$ & $93(48 \%)$ & $192(85 \%)$ \\
\hline Mortality & $56(40 \%)$ & $12(9 \%)$ & $4(3 \%)$ & $68(49 \%)$ & $140(62 \%)$ \\
\hline Readmission & $3(25 \%)$ & $1(8 \%)$ & $3(25 \%)$ & $5(42 \%)$ & $12(5 \%)$ \\
\hline Complication/morbidity & $0(0 \%)$ & $12(46 \%)$ & $1(4 \%)$ & $13(50 \%)$ & $26(12 \%)$ \\
\hline Quality of Life Index (QoL) & $3(23 \%)$ & $1(8 \%)$ & $3(23 \%)$ & $6(46 \%)$ & $13(6 \%)$ \\
\hline Composite measure & $0(0 \%)$ & $0(0 \%)$ & $0(0 \%)$ & $1(100 \%)$ & $1(05 \%)$ \\
\hline Process measures & $14(43 \%)$ & $7(21 \%)$ & $\mathbf{0}(\mathbf{0} \%)$ & $12(36 \%)$ & $33(15 \%)$ \\
\hline Process (unspecified) & $1(100 \%)$ & $0(0 \%)$ & $0(0 \%)$ & $0(0 \%)$ & $1(05 \%)$ \\
\hline CABG process measure & $2(29 \%)$ & $3(43 \%)$ & $0(0 \%)$ & $2(29 \%)$ & $7(3 \%)$ \\
\hline Pneumonia process measure & $0(0 \%)$ & $4(33 \%)$ & $0(0 \%)$ & $8(67 \%)$ & $12(5 \%)$ \\
\hline $\mathrm{CHF}$ process measure & $4(80 \%)$ & $0(0 \%)$ & $0(0 \%)$ & $1(20 \%)$ & $5(2 \%)$ \\
\hline AMI process measure & $1(100 \%)$ & $0(0 \%)$ & $0(0 \%)$ & $0(0 \%)$ & $1(05 \%)$ \\
\hline Stroke process measure & $6(86 \%)$ & $0(0 \%)$ & $0(0 \%)$ & $1(14 \%)$ & $7(3 \%)$ \\
\hline \multicolumn{6}{|l|}{ Clinical conditions } \\
\hline AMI & $21(70 \%)$ & $0(0 \%)$ & $0(0 \%)$ & $9(30 \%)$ & $30(135 \%)$ \\
\hline $\mathrm{CHF}$ & $12(63 \%)$ & $4(21 \%)$ & $0(0 \%)$ & $3(16 \%)$ & $19(8 \%)$ \\
\hline Pneumonia & $1(5 \%)$ & $6(30 \%)$ & $0(0 \%)$ & $13(65 \%)$ & $20(9 \%)$ \\
\hline Stroke & $14(50 \%)$ & $0(0 \%)$ & $2(7 \%)$ & $12(43 \%)$ & $28(125 \%)$ \\
\hline CABG & $2(18 \%)$ & $4(36 \%)$ & $0(0 \%)$ & $5(45 \%)$ & $11(5 \%)$ \\
\hline Hip fracture/replacement & $1(8 \%)$ & $1(8 \%)$ & $4(33 \%)$ & $6(50 \%)$ & $12(5 \%)$ \\
\hline Other surgical procedures & $5(16 \%)$ & $12(38 \%)$ & $3(9 \%)$ & $12(38 \%)$ & $32(14 \%)$ \\
\hline Other medical conditions & $11(22 \%)$ & $4(8 \%)$ & $2(4 \%)$ & $32(65 \%)$ & $49(22 \%)$ \\
\hline Not available conditions & $9(38 \%)$ & $2(8 \%)$ & $0(0 \%)$ & $13(54 \%)$ & $24(11 \%)$ \\
\hline \multicolumn{6}{|l|}{ Country } \\
\hline Canada & $2(100 \%)$ & $0(0 \%)$ & $0(0 \%)$ & $0(0 \%)$ & $2(1 \%)$ \\
\hline Germany & $2(50 \%)$ & $0(0 \%)$ & $0(0 \%)$ & $2(50 \%)$ & $4(2 \%)$ \\
\hline Italy & $3(75 \%)$ & $0(0 \%)$ & $0(0 \%)$ & $1(25 \%)$ & $4(2 \%)$ \\
\hline $\begin{array}{l}\text { Nordic countries (Denmark, Estonia, } \\
\text { Finland, Iceland, Norway, Sweden) }\end{array}$ & $8(25 \%)$ & $4(1 \%)$ & $3(9 \%)$ & $17(53 \%)$ & $32(14 \%)$ \\
\hline Japan & $6(60 \%)$ & $0(0 \%)$ & $0(0 \%)$ & $4(40 \%)$ & $10(4 \%)$ \\
\hline Korea & $0(0 \%)$ & $0(0 \%)$ & $0(0 \%)$ & $1(100 \%)$ & $1(05 \%)$ \\
\hline France & $0(0 \%)$ & $0(0 \%)$ & $0(0 \%)$ & $2(100 \%)$ & $2(1 \%)$ \\
\hline Hungary & $2(50 \%)$ & $0(0 \%)$ & $1(25 \%)$ & $1(25 \%)$ & $4(2 \%)$ \\
\hline Spain & $0(0 \%)$ & $0(0 \%)$ & $0(0 \%)$ & $2(100 \%)$ & $2(1 \%)$ \\
\hline UK & $1(9 \%)$ & $1(9 \%)$ & $3(27 \%)$ & $6(55 \%)$ & $11(5 \%)$ \\
\hline USA & $49(33 \%)$ & $28(19 \%)$ & $4(3 \%)$ & $67(45 \%)$ & $148(66 \%)$ \\
\hline Pooled Sample & $3(60 \%)$ & $0(0 \%)$ & $0(0 \%)$ & $2(40 \%)$ & $5(25 \%)$ \\
\hline \multicolumn{6}{|l|}{ Year } \\
\hline 1990-1999 & $3(8 \%)$ & $5(14 \%)$ & $4(11 \%)$ & $25(68 \%)$ & $37(16 \%)$ \\
\hline 2000-2009 & $14(41 \%)$ & $2(6 \%)$ & $0(0 \%)$ & $18(53 \%)$ & $34(15 \%)$ \\
\hline 2010-2019 & $59(38 \%)$ & $26(17 \%)$ & $7(5 \%)$ & $62(40 \%)$ & $154(69 \%)$ \\
\hline
\end{tabular}


Table 2 (continued)

\begin{tabular}{lllll}
$\begin{array}{l}\text { Sign linear/non- } \\
\text { linear positive }\end{array}$ & Sign linear negative & $\begin{array}{l}\text { Sign non-linear } \\
\text { U-shaped/ inverted } \\
\text { U-shaped } \\
(n)(\% \text { of ni })\end{array}$ & Not sign & Total \\
& $(n)(\%)$ of ni) $)$ & 0 of ni) & $\left(n_{\mathrm{i}}\right)(\%$ of 225) \\
$2(25 \%)$ & $0(0 \%)$ & $0(0 \%)$ & $6(75 \%)$ & $\mathbf{8}(\mathbf{4 \%})$ \\
$47(29 \%)$ & $29(18 \%)$ & $5(3 \%)$ & $82(50 \%)$ & $\mathbf{1 6 3}(\mathbf{7 2 \%})$ \\
$27(50 \%)$ & $4(7 \%)$ & $6(11 \%)$ & $17(32 \%)$ & $\mathbf{5 4}(\mathbf{2 4 \%})$ \\
\hline
\end{tabular}

$C f O$ controlling for observables, $C f U$ controlling for unobservables, $I V$ instrumental variable

are partially contradictory to those reported by Hussey et al. [9], who found nonsignificant or mixed findings in only $26 \%$ of their studies. Some differences can be explained by our inclusion of price instead of only costs, the inclusion of the clinical conditions investigated in each paper, the addition of countries other than the USA, and the longer time frame, all leading to increases in the share of nonsignificant findings. Moreover, a large part might also be due to differences in the classification of the results and the level of aggregation (study level vs association level).

In summary, we find highly mixed evidence of the association. One potential explanation is the multiple ways that price and cost can relate to the quality of care. Another explanation might be the high heterogeneity across the included studies. Most notably, the overall pattern of the relationships between hospitals' price-quality and costquality were quite similar. Indeed, some variations can be explained by the studies' characteristics. In particular, we find that the proportion of studies that detected a significantly positive association is higher when: (a) price/reimbursement is used (instead of cost); (b) process measures are used (instead of outcome measures); (c) the focus is on AMI, $\mathrm{CHF}$, and stroke patients (instead of patients with other clinical conditions or all patients); and (d) the methodological approach used to address confounding is more sophisticated. In the following, we discuss the extent to which these results can be explained to increase our understanding of the cost/ price-quality of care relationship.

Regarding our findings, the share of positive associations between cost/price and the quality of care is higher when price is assessed instead of cost. One potential mechanism implies that in the face of a price increase for a particular diagnosis or treatment, more patients may be admitted to the hospital (i.e. volume increases), which could lead to a higher quality of care due to institutional learning [8, 17, 18]. Moreover, higher prices might enable hospitals to spend more on service provision, which might have a positive effect on the quality of care. This line of argument is supported by prior evidence showing that when the price/ cost margins are high, hospitals may compete in quality to attract more patients [19]. This view is also consistent with the traditional profit-maximization model of hospital behavior, which predicts that a reduction in price will lead to a reduction in quality [3]. However, the profit-maximization model might not adequately describe a hospital's decision making because a high proportion of hospitals are organized as not-for-profit institutions. Therefore, as described in Newhouse's [21] theory of nonprofit behavior, hospitals use the excess of payments over costs for those patient groups that are profitable to expand the quality of services [20, 21].

Based on our findings, the share of positive associations between cost/price and the quality of care is higher when process rather than outcome measures are assessed. Process measures might be more sensitive to changes in a hospital's cost/price and more reflective of the factors under the hospital's control than outcome measures [22]. Moreover, changes in process measures might affect the hospital cost. For example, providing appropriate care frequently requires additional physician visits and medications [23].

Regarding our findings, the share of positive associations between cost/price and the quality of care is higher when the focus is on AMI, CHF, and/or stroke patients (instead of patients with other clinical conditions or all patients). Notably, in contrast to many other conditions, $\mathrm{AMI}, \mathrm{CHF}$, and stroke are emergency conditions. For these conditions, the steering and organization of emergency pathways (e.g. centralization and telemedicine) lead to an increase in patients, and costs are higher due to 24/7 infrastructure and operation (contingency) costs. In this case, quality (particularly mortality measures) should also increase because of the volume/outcome relationship.

Based on our findings, the share of positive associations between cost/price and the quality of care is higher when the methodological approach used to address confounding is more advanced. Endogeneity is clearly an issue in the price/ cost-quality relationship, e.g. due to the high risk of omitted variable bias (e.g. insufficient risk adjustment, unobserved variations in hospital equipment and organization of service provision). If methods that more appropriately rule out endogeneity bias find stronger support, this might imply that the other studies underestimate the true effect. 
Table 3 Overview on study findings on the price-quality relationship in total and for different subcategories

\begin{tabular}{|c|c|c|c|c|}
\hline & $\begin{array}{l}\text { Sign linear positive } \\
\text { (n) }(\% \text { of ni) }\end{array}$ & $\begin{array}{l}\text { Sign linear negative } \\
\text { (n) }(\% \text { of ni) }\end{array}$ & $\begin{array}{l}\text { Not sign } \\
(n)(\% \text { of ni) }\end{array}$ & $\begin{array}{l}\text { Total } \\
\text { (ni) (\% of } 60)\end{array}$ \\
\hline Total price/reimbursement & $22(37 \%)$ & $7(115 \%)$ & $31(515 \%)$ & $60(100 \%)$ \\
\hline \multicolumn{5}{|l|}{ Quality of care measure } \\
\hline Outcome & $16(30 \%)$ & $7(13 \%)$ & $21(39 \%)$ & $53(88 \%)$ \\
\hline Mortality & $16(40 \%)$ & $4(10 \%)$ & $20(50 \%)$ & $40(67 \%)$ \\
\hline Readmission & $0(0 \%)$ & $0(0 \%)$ & $1(100 \%)$ & $1(1 \%)$ \\
\hline Complication/morbidity & $0(0 \%)$ & $3(25 \%)$ & $9(75 \%)$ & $12(20 \%)$ \\
\hline Process measures & $6(86 \%)$ & $\mathbf{0}(\mathbf{0} \%)$ & $1(14 \%)$ & $7(12 \%)$ \\
\hline Stroke process measure & $6(86 \%)$ & $0(0 \%)$ & $1(14 \%)$ & $7(12 \%)$ \\
\hline \multicolumn{5}{|l|}{ Clinical conditions } \\
\hline AMI & $4(67 \%)$ & $0(0 \%)$ & $2(33 \%)$ & $6(10 \%)$ \\
\hline $\mathrm{CHF}$ & $2(67 \%)$ & $1(34 \%)$ & $0(0 \%)$ & $3(5 \%)$ \\
\hline Stroke & $9(75 \%)$ & $0(0 \%)$ & $3(25 \%)$ & $12(20 \%)$ \\
\hline Pneumonia & $0(0 \%)$ & $1(34 \%)$ & $2(66 \%)$ & $3(5)$ \\
\hline Hip fracture/replacement & $1(100 \%)$ & $0(0 \%)$ & $0(0 \%)$ & $1(15 \%)$ \\
\hline Other surgical procedures & $4(57 \%)$ & $3(43 \%)$ & $0(0 \%)$ & $7(115 \%)$ \\
\hline Other medical conditions & $2(85 \%)$ & $2(85 \%)$ & $20(83 \%)$ & $24(40 \%)$ \\
\hline Not available conditions & $0(0 \%)$ & $0(0 \%)$ & $4(100 \%)$ & $4(7 \%)$ \\
\hline \multicolumn{5}{|l|}{ Country } \\
\hline Germany & $1(100 \%)$ & $0(0 \%)$ & $0(0 \%)$ & $1(2 \%)$ \\
\hline Japan & $6(60 \%)$ & $0(0 \%)$ & $3(40 \%)$ & $9(15 \%)$ \\
\hline USA & $15(30 \%)$ & $7(14 \%)$ & $28(56 \%)$ & $50(83 \%)$ \\
\hline \multicolumn{5}{|l|}{ Year } \\
\hline 1990-1999 & $1(4 \%)$ & $3(11 \%)$ & $22(85 \%)$ & $26(43 \%)$ \\
\hline 2000-2009 & $0(0 \%)$ & $0(0 \%)$ & $4(100 \%)$ & $4(7 \%)$ \\
\hline 2010-2018 & $21(70 \%)$ & $4(13 \%)$ & $5(17 \%)$ & $30(50 \%)$ \\
\hline \multicolumn{5}{|l|}{ Methods } \\
\hline $\begin{array}{l}\text { CfO a multivariable model } \\
\text { (cross-section) }\end{array}$ & $6(67 \%)$ & $0(0 \%)$ & $3(34 \%)$ & $9(15 \%)$ \\
\hline CfO b multivariate model & $9(21 \%)$ & $7(16 \%)$ & $27(63 \%)$ & $43(72 \%)$ \\
\hline CfU_IV approaches & $7(875 \%)$ & $0(0 \%)$ & $1(125 \%)$ & $8(13 \%)$ \\
\hline
\end{tabular}

$C f O$ controlling for observables, $C f U$ controlling for unobservables, $I V$ instrumental variable
During our analysis, we observed that only a small share of studies tested for a nonlinear cost-quality relationship. Among these studies, U-shaped/inverted U-shapes relationships were assessed mostly in studies using more advanced econometric methods (e.g. the IV approach) and those concentrating on hip fracture/replacement conditions.

The current systematic review is subject to several limitations. First, the heterogeneity in the studies' criteria limited our ability to perform a quantitative synthesis or any other comparisons across the studies. In addition, this review was limited by the quality of the included studies. Moreover, there is a possibility of publication bias because no gray literature was searched, and non-English language publications were excluded.

Although our study may answer important questions regarding the association between cost/price and the quality of care, other related questions may remain unanswered.
Given our findings, we observed some differences in the associations between surgical and medical conditions. Future work could explain the reason for these differences. Additionally, we focus on several critical design characteristics that may alter the association between cost/price and the quality of care; however, some other characteristics, such as market characteristics (e.g. competition), might be able to explain some differences in the cost/price-quality relationship. ${ }^{2}$ For example, hospitals with a large number of beds relative to the population size might have more competition for nurses, which increases labor costs [24]. This review also suggests that more research is needed to generate robust evidence regarding the association between cost/price and the quality of care.

In conclusion, our review suggests that there is no general relationship between cost/price and the quality of care.

\footnotetext{
$\overline{2}$ None of the included studies controlled for such covariates.
} 
However, when accounting for endogeneity, the evidence suggests that a positive relationship exists. Additionally, the relationship appears to depend on the condition and the specific resource utilization. Thus, the potential to increase the quality of care while maintaining or reducing the price and cost levels is low for several conditions, while for other conditions, the evidence is inconclusive. Moreover, different countries/regions have different regulations for quality assurance (e.g. staffing regulation, mortality and morbidityconferences, technology use, and minimum volumes), which clearly has an effect on cost and quality. Therefore, policy makers should be prudent with the measures used to reduce hospital costs to avoid endangering the quality of care, especially in resource-sensitive settings.

Acknowledgments Open Access funding provided by Projekt DEAL.

Author Contributions VW and SJ conceptualized and wrote the manuscript, which was critically reviewed and extended by JS; the data extraction protocol was drafted by SJ; and the validation of the data extraction (tables) was performed by SJ and VW. All authors discussed the results and contributed to the final manuscript, and all authors approved the manuscript.

Data Availability Statement The authors confirm that all relevant data are included in the article and/or its supplementary information files.

\section{Compliance with Ethical Standards}

Conflict of Interest Sara Jamalabadi, Vera Winter, and Jonas Schreyögg declare that they have no conflicts of interest.

Funding This project received funding from the European Union's Horizon 2020 Research and Innovation Programme under the Marie Skłodowska-Curie grant agreement "No 721402".

Open Access This article is licensed under a Creative Commons Attribution-NonCommercial 4.0 International License, which permits any non-commercial use, sharing, adaptation, distribution and reproduction in any medium or format, as long as you give appropriate credit to the original author(s) and the source, provide a link to the Creative Commons licence, and indicate if changes were made. The images or other third party material in this article are included in the article's Creative Commons licence, unless indicated otherwise in a credit line to the material. If material is not included in the article's Creative Commons licence and your intended use is not permitted by statutory regulation or exceeds the permitted use, you will need to obtain permission directly from the copyright holder.To view a copy of this licence, visit http://creativecommons.org/licenses/by-nc/4.0/.

\section{References}

1. Häkkinen U, Rosenqvist G, Iversen T, Rehnberg C, Seppälä TT, Group Es. Outcome, use of resources and their relationship in the treatment of AMI, stroke and hip fracture at European hospitals. Health Econ. 2015;24:116-39.

2. Brown EC. Irrational hospital pricing. Hous J Health L \& Pol'y. 2014; $14: 11$
3. Hodgkin D, McGuire TG. Payment levels and hospital response to prospective payment. J Health Econ. 1994;13(1):1-29.

4. Dafny LS. How do hospitals respond to price changes? Am Econ Rev. 2005;95(5):1525-47.

5. Street A, Vitikainen K, Bjorvatn A, Hvenegaard A. Introducing activity-based financing: a review of experience in Australia, Denmark, Norway and Sweden. 2007.

6. Januleviciute J, Askildsen JE, Kaarboe O, Siciliani L, Sutton M. How do hospitals respond to price changes? Evid Norway Health Econ. 2016;25(5):620-36.

7. Siciliani L. Empirical market models. 2014:277-81.

8. Fleming ST. The relationship between quality and cost: pure and simple? Inquiry 1991:29-38.

9. Hussey PS, Wertheimer S, Mehrotra A. The association between health care quality and cost: a systematic review. Ann Intern Med. 2013;158(1):27-34.

10. Sorenson C, Drummond M, Khan BB. Medical technology as a key driver of rising health expenditure: disentangling the relationship. Clin Econ Outcomes Res CEOR. 2013;5:223.

11. Moher D, Liberati A, Tetzlaff J, Altman DG. Preferred reporting items for systematic reviews and meta-analyses: the PRISMA statement. Ann Intern Med. 2009;151(4):264-9.

12. Schardt C, Adams MB, Owens T, Keitz S, Fontelo P. Utilization of the PICO framework to improve searching PubMed for clinical questions. BMC Med Inform Decis Mak. 2007;7(1):16.

13. Cutler DM. The incidence of adverse medical outcomes under prospective payments: National Bureau of Economic Research 1993.

14. Duggan MG. Hospital ownership and public medical spending. Q J Econ. 2000;115(4):1343-73.

15. Stargardt T, Schreyögg J, Kondofersky I. Measuring the relationship between costs and outcomes: the example of acute myocardial infarction in German hospitals. Health Econ. 2014;23(6):653-69.

16. Krousel-Wood M. Practical considerations in the measurement of outcomes in healthcare. Ochsner J. 1999;1(4):187-94.

17. Brekke KR, Siciliani L, Straume OR. Hospital competition and quality with regulated prices. Scand J Econ. 2011;113(2):444-69.

18. Gaynor M, Seider H, Vogt WB. The volume-outcome effect, scale economies, and learning-by-doing. Am Econ Rev. 2005;95(2):243-7.

19. Dranove D, White WD. Medicaid-dependent hospitals and their patients: how have they fared? Health Serv Res. 1998;33(2 Pt 1): 163 .

20. Bazzoli GJ, Chen HF, Zhao M, Lindrooth RC. Hospital financial condition and the quality of patient care. Health Econ. 2008;17(8):977-95.

21. Newhouse JP. Toward a theory of nonprofit institutions: an economic model of a hospital. Am Econ Rev. 1970;60(1):64-74.

22. Volpp KG, Konetzka RT, Zhu J, Parsons L, Peterson E. Effect of cuts in Medicare reimbursement on process and outcome of care for acute myocardial infarction patients. Circulation. 2005;112(15):2268-75

23. Nuckols TK, Escarce JJ, Asch SM. The effects of quality of care on costs: a conceptual framework. Milbank Quart. 2013;91(2):316-53.

24. Dranove D, Shanley M, White WD. Price and concentration in hospital markets: the switch from patient-driven to payer-driven competition. J Law Econ. 1993;36(1):179-204.

25. Auerbach AD, Hilton JF, Maselli J, Pekow PS, Rothberg MB, Lindenauer PK. Case volume, quality of care, and care efficiency in coronary artery bypass surgery. Arch Intern Med. 2010;170(14):1202-8.

26. Birkmeyer JD, Dimick JB, Birkmeyer NJ. Measuring the quality of surgical care: structure, process, or outcomes? J Am Coll Surg. 2004; 198(4):626-32. 
27. Bradbury R, Golec J, Steen P. Toward a systems quality paradigm: relating health outcomes, resource expenditures, and appropriateness of cholecystectomy patients. Health Serv Manag Res. 1997;10(4):231-44.

28. Bradbury RC, Golec JH, Steen PM. Relating hospital health outcomes and resource expenditures. Inquiry. 1994:56-65.

29. Broderick RC, Fuchs HF, Harnsberger CR, Chang DC, McLemore $\mathrm{E}$, Ramamoorthy $\mathrm{S}$, et al. The price of decreased mortality in the operative management of diverticulitis. Surg Endosc. 2015;29(5):1185-91.

30. Carey K, Burgess JF Jr. On measuring the hospital cost/quality trade-off. Health Econ. 1999;8(6):509-20.

31. Chan T, Kim J, Minich LL, Pinto NM, Waitzman NJ. Surgical volume, hospital quality, and hospitalization cost in congenital heart surgery in the United States. Pediatr Cardiol. 2015;36(1):205-13.

32. Chen LM, Jha AK, Guterman S, Ridgway AB, Orav EJ, Epstein AM. Hospital cost of care, quality of care, and readmission rates: penny wise and pound foolish? Arch Intern Med. 2010;170(4):340-6.

33. Cohen D, Manuel DG, Tugwell P, Sanmartin C, Ramsay T. Does higher spending improve survival outcomes for myocardial infarction? Examining the cost-outcomes relationship using time-varying covariates. Health Serv Res. 2015;50(5):1589-605.

34. Deily ME, McKay NL. Cost inefficiency and mortality rates in Florida hospitals. Health Econ. 2006;15(4):419-31.

35. Doyle JJ Jr, Graves JA, Gruber J, Kleiner SA. Measuring returns to hospital care: evidence from ambulance referral patterns. J Polit Econ. 2015;123(1):170-21414

36. Gani F, Ejaz A, Makary MA, Pawlik TM. Hospital markup and operation outcomes in the United States. Surgery. 2016;160(1):169-77.

37. Glance LG, Dick AW, Osler TM, Meredith W, Mukamel DB. The association between cost and quality in trauma: is greater spending associated with higher-quality care? Ann Surg. 2010;252(2):217-22.

38. Gupta P, Rettiganti M. Relationship of hospital costs with mortality in pediatric critical care: a multi-institutional analysis. Pediatr Crit Care Med. 2017;18(6):541-9.

39. Gutacker N, Bojke C, Daidone S, Devlin NJ, Parkin D, Street A. TRULY INEFFICIENT OR providing better quality of care? analysing the relationship between risk-adjusted hospital costs and patients' health outcomes. Health Econ. 2013;22(8):931-47.

40. Haas L, Stargardt T, Schreyoegg J, Schlösser R, Klapp BF, Danzer G. The trade-off between costs and quality of care in the treatment of psychosomatic patients with somatoform pain disorder. Appl Health Econ Health Policy. 2013;11(4):359-68.

41. Hadley J, Waidmann T, Zuckerman S, Berenson RA. Medical spending and the health of the elderly. Health Serv Res. 2011;46(5):1333-611.

42. Häkkinen U, Rosenqvist G, Peltola M, Kapiainen S, Rättö H, Cots F, et al. Quality, cost, and their trade-off in treating AMI and stroke patients in European hospitals. Health Policy. 2014;117(1):15-27.

43. Anne H, Nielsen Arendt J, Gyrd-Hansen D, Street A. Exploring the relationship between costs and quality - Does the joint evaluation of costs and quality alter the ranking of Danish hospital departments?: COHERE-Centre of Health Economics Research, University of Southern Denmark 2010.

44. Jha AK, Orav EJ, Dobson A, Book RA, Epstein AM. Measuring efficiency: the association of hospital costs and quality of care. Health Aff. 2009;28(3):897-906.

45. Kaestner R, Silber JH. Evidence on the efficacy of inpatient spending on Medicare patients. Milbank Quart. 2010;88(4):560-94.
46. Kang H-C, Hong J-S. Association between costs and quality of acute myocardial infarction care hospitals under the Korea National Health Insurance program. Medicine. 2017;96(31).

47. Kittelsen SA, Anthun KS, Goude F, Huitfeldt IM, Häkkinen U, Kruse M, et al. Costs and quality at the hospital level in the Nordic countries. Health Econ. 2015;24:140-63.

48. Kruse M, Christensen J. Is quality costly? Patient and hospital cost drivers in vascular surgery. Health Econ Rev. 2013;3(1):22.

49. Lagu T, Rothberg MB, Nathanson BH, Pekow PS, Steingrub JS, Lindenauer PK. The relationship between hospital spending and mortality in patients with sepsis. Arch Intern Med. 2011;171(4):292-9.

50. Lee J, Morishima T, Park S, Otsubo T, Ikai H, Imanaka Y. The association between health care spending and quality of care for stroke patients in Japan. J Health Serv Res Policy. 2013;18(2):77-82.

51. McKay NL, Deily ME. Cost inefficiency and hospital health outcomes. Health Econ. 2008;17(7):833-48.

52. Morey RC, Fine DJ, Loree SW, Retzlaff-Roberts DL, Tsubakitani S. The trade-off between hospital cost and quality of care: an exploratory empirical analysis. Medical Care. 1992:677-98.

53. Mukamel DB, Zwanziger J, Tomaszewski KJ. HMO penetration, competition, and risk-adjusted hospital mortality. Health Serv Res. 2001;36(6 Pt 1):1019.

54. Mukamel DB, Zwanziger J, Bamezai A. Hospital competition, resource allocation and quality of care. BMC Health Serv Res. 2002;2(1):10.

55. Ong MK, Mangione CM, Romano PS, Zhou Q, Auerbach AD, Chun A, et al. Looking forward, looking back: assessing variations in hospital resource use and outcomes for elderly patients with heart failure. Circulation. 2009;2(6):548-57.

56. Osnabrugge RL, Speir AM, Head SJ, Jones PG, Ailawadi G, Fonner CE, et al. Cost, quality, and value in coronary artery bypass grafting. J Thorac Cardiovasc Surg. 2014;148(6):2729-35.

57. Pasquali SK, Jacobs JP, Bove EL, Gaynor JW, He X, Gaies MG, et al. Quality-cost relationship in congenital heart surgery. Ann Thorac Surg. 2015;100(4):1416-21.

58. Picone GA, Sloan FA, Chou S-Y, Taylor DH Jr. Does higher hospital cost imply higher quality of care? Rev Econ Stat. 2003;85(1):51-62.

59. Romley JA, Jena AB, Goldman DP. Hospital spending and inpatient mortality: evidence from California: an observational study. Ann Intern Med. 2011;154(3):160-7.

60. Romley JA, Jena AB, O'Leary JF, Goldman DP. Spending and mortality in US acute care hospitals. Am J Manag Care. 2013;19(2):e46.

61. Romley JA, Chen AY, Goldman DP, Williams R. Hospital costs and inpatient mortality among children undergoing surgery for congenital heart disease. Health Serv Res. 2014;49(2):588-608.

62. Saleh S, Callan M, Kassak K. The association between the hospital quality alliance's pneumonia measures and discharge costs. J Health Care Finance. 2012;38(3):50-60.

63. Sasaki N, Kunisawa S, Ikai H, Imanaka Y. Differences between determinants of in-hospital mortality and hospitalisation costs for patients with acute heart failure: a nationwide observational study from Japan. BMJ Open. 2017;7(3):e013753. https://doi. org/10.1136/bmjopen-2016-013753.

64. Schreyögg J, Stargardt T. The trade-off between costs and outcomes: the case of acute myocardial infarction. Health Serv Res. 2010;45(6): 1585-601.

65. Yeh JL, Wu S, Wu BU. Regional cost variation for acute pancreatitis in the US. JOP J Pancr. 2014;15(5):448-54. 